\title{
Visualizing spatiotemporal dynamics of apoptosis after G1 arrest by human T cell leukemia virus type 1 Tax and insights into gene expression changes using microarray-based gene expression analysis
}

Mariluz Arainga ${ }^{1,2}$, Hironobu Murakami $i^{1,3}$ and Yoko Aida $a^{1,2^{*}}$

\begin{abstract}
Background: Human T cell leukemia virus type 1 (HTLV-1) Tax is a potent activator of viral and cellular gene expression that interacts with a number of cellular proteins. Many reports show that Tax is capable of regulating cell cycle progression and apoptosis both positively and negatively. However, it still remains to understand why the Tax oncoprotein induces cell cycle arrest and apoptosis, or whether Tax-induced apoptosis is dependent upon its ability to induce $G_{1}$ arrest. The present study used time-lapse imaging to explore the spatiotemporal patterns of cell cycle dynamics in Tax-expressing HeLa cells containing the fluorescent ubiquitination-based cell cycle indicator, Fucci2. A large-scale host cell gene profiling approach was also used to identify the genes involved in Tax-mediated cell signaling events related to cellular proliferation and apoptosis.

Results: Tax-expressing apoptotic cells showed a rounded morphology and detached from the culture dish after cell cycle arrest at the $G_{1}$ phase. Thus, it appears that Tax induces apoptosis through pathways identical to those involved in $G_{1}$ arrest. To elucidate the mechanism(s) by which Tax induces cell cycle arrest and apoptosis, regulation of host cellular genes by Tax was analyzed using a microarray containing approximately 18,400 human mRNA transcripts. Seventeen genes related to cell cycle regulation were identified as being up or downregulated > 2.0-fold in Tax-expressing cells. Several genes, including SMAD3, JUN, GADD45B, DUSP1 and IL8, were involved in cellular proliferation, responses to cellular stress and DNA damage, or inflammation and immune responses. Additionally, 23 pro- and anti-apoptotic genes were deregulated by Tax, including TNFAIP3, TNFRS9, BIRC3 and IL6. Furthermore, the kinetics of IL8, SMAD3, CDKN1A, GADD45A, GADD45B and IL6 expression were altered following the induction of Tax, and correlated closely with the morphological changes observed by time-lapse imaging.

Conclusions: Taken together, the results of this study permit a greater understanding of the biological events affected by HTLV-1 Tax, particularly the regulation of cellular proliferation and apoptosis. Importantly, this study is the first to demonstrate the dynamics of morphological changes during Tax-induced apoptosis after cell cycle arrest at the $G_{1}$ phase.
\end{abstract}

\footnotetext{
* Correspondence: aida@riken.jp

${ }^{1}$ Viral Infectious Diseases Unit, RIKEN, 2-1 Hirosawa, Wako, Saitama 351-0198,

Japan

Department of Medical Genome Sciences, Graduate School of Frontier

Science, Laboratory of Viral Infectious Diseases, The University of Tokyo, 2-1

Hirosawa, Wako, Saitama 351-0198, Japan

Full list of author information is available at the end of the article
} 


\section{Background}

Human T cell leukemia virus type 1 (HTLV-1) causes adult $\mathrm{T}$ cell leukemia (ATL), a severe and fatal lymphoproliferative disease of helper T cells [1], and a separate neurodegenerative disease called tropical spastic paraparesis/HTLV-1-associated myelopathy (TSP/HAM) [2]. HTLV-1 encodes a $40 \mathrm{kDa}$ regulatory protein, Tax, which is necessary and sufficient for cellular transformation and is, therefore, considered to be the viral oncoprotein. Tax is a potent activator of both viral and cellular gene expression, and the oncogenic potential of Tax is thought to depend on its ability to alter the expression of cellular genes involved in cell growth and proliferation, and its direct interactions with cell cycle regulators [3,4]. Tax-mediated transcriptional activation of cellular gene expression requires direct contact with components of the cyclic AMP-response element binding protein (CREB), nuclear factor- $\mathrm{kB}$ (NF- $\mathrm{kB})$, and the serum response factor (SRF) signaling pathways [5]. Moreover, Tax is thought to be involved in other cellular processes including DNA repair, cell cycle progression, and apoptosis [6,7].

Tax stimulates cell growth via cell cycle dysregulation $[3,4,7]$. A major mitogenic activity of Tax is stimulation of the $\mathrm{G}_{1}$-to-S-phase transition [8-12], and several different mechanisms have been proposed to explain the dysregulation of the $G_{1}$ phase and the accelerated progression into $S$ phase. In mammalian cells, $G_{1}$ progression is controlled by the sequential activation of the cyclin-dependent kinases (Cdks) Cdk4, Cdk6, and Cdk2. Activation of these Cdks by Tax leads to hyperphosphorylation of Retinoblastoma (Rb) and the liberation of E2F, which is essential for cell cycle progression [12,13]. Tax interacts with cyclins D1, D2, and D3, but not with Cdk1 or Cdk2 [11,14-16]. By binding to cyclins, Tax stabilizes the cyclin $\mathrm{D} / \mathrm{Cdk}$ complex, thereby enhancing its kinase activity and leading to the hyperphosphorylation of $\mathrm{Rb}$. Moreover, Tax activates the transcription of cyclin D1 and D2 $[17,18]$ by deregulating the NF- $\mathrm{kB}$ pathway $[18,19]$. By contrast, there is evidence that Tax induces cell cycle arrest at the $G_{1}$ phase [20]. HTLV-1 infection and Tax expression in human cells have been observed to induce cell cycle arrest at the $G_{1}$ phase by inducing p27/kip1 and p21/waf1 [20], and the sharp rise in p27 induced by Tax is often associated with premature activation of the anaphase-promoting complex (APC) [21]. Indeed, cells infected with HTLV-1 expressing wild-type Tax arrest at the $G_{1} / S$ boundary when subjected to cellular stress [22,23].

Interestingly, Tax induces apoptosis in a variety of systems [24-26], consistent with its ability to inhibit DNA repair. Indeed, HTLV-1-infected cells undergo increased apoptosis upon cellular stress [22-28]; however, other reports show that Tax inhibits apoptosis [29-31], supporting its role as a transforming protein and an inducer of $\mathrm{T}$ cell proliferation. Therefore, it seems likely that Tax is capable of stimulating both pro- and antiapoptotic pathways.

Tax regulates cell cycle progression and apoptosis both positively and negatively; however, the molecular mechanism(s) underlying the regulation of these processes by Tax remain obscure. In this study, we examined the regulation of cell cycle progression and apoptosis by Tax and demonstrated the following: (i) a high level of transient Tax expression arrests the cell cycle at the $G_{1}$ phase and induces apoptosis in HeLa cells; (ii) based on a microarray containing approximately 18,400 human mRNA transcripts, genes related to cell cycle progression and apoptosis were deregulated by Tax in HeLa cells; (iii) time-lapse imaging of a fluorescent ubiquitination-based cell cycle indicator (Fucci2) in HeLa cells allows for dual-color imaging and can be used to distinguish between live cells in the $G_{1}$ and $\mathrm{S} / \mathrm{G}_{2} / \mathrm{M}$ phases. Using this system for the in vivo analysis of the spatial and temporal patterns of cell cycle dynamics [32,33], we demonstrated that Tax-expressing cells arrest in the $G_{1}$ phase of the cell cycle and proceeded to apoptosis; and (iv) we found that Tax-induced changes in the expression of genes related to cell cycle regulation and apoptosis correlated well with the morphological changes observed in the cells.

\section{Results}

Tax induces cell cycle arrest and apoptosis in transfected HeLa cells

To examine whether Tax induces cell cycle arrest at the $\mathrm{G}_{1}$ phase and promotes apoptosis in HeLa cells, chimeric Tax carrying a Flag tag at the carboxyl terminus was transfected into HeLa cells. At $24 \mathrm{~h}$ post transfection, the expression of Tax protein was assessed by immunoblot analysis of cell extracts using the monoclonal antibody (MAb) M2, which recognizes the Flag tag (Figure 1A). A single band with an apparent molecular mass consistent with the predicted sequences was observed. As shown in Figure 1B, Tax was detected in both the nucleus and cytoplasm of transfected HeLa cells. This result correlates well with previous studies indicating that Tax is able to shuttle between the nucleus and the cytoplasm but predominantly localizes in the nucleus [34]. As shown in Figure 1C, Tax showed considerable transactivation activity toward the HTLV-1 enhancer, indicating that chimeric Tax with a C-terminal Flag tag was fully functional.

Next, the cell cycle distribution of Tax-expressing HeLa cells was analyzed. Cells were stained with propidium iodide (PI) and analyzed by flow cytometry $48 \mathrm{~h}$ after co-transfection with the Tax expression vector or the control vector and a green fluorescence protein (GFP) expression vector, pEGFP-N1, which served as a 




Figure 1 Tax induces $\mathbf{G}_{1}$ cell cycle arrest and apoptosis. HeLa cells were transiently transfected with a pCAGGS-Tax Flag-tagged vector or the control pCAGGS vector (A, B and $\mathbf{E}$ ) together with either the reporter plasmid pGV-HL21 (HTLV-1 enhancer) and the reference plasmid pRL-SV40 (C), or the GFP expression vector pEGFP-NI (D and $\mathbf{G}$ ) or the pSV- $\beta$-galactosidase vector (F). (A) At $24 \mathrm{~h}$ post-transfection, cells were lysed and subjected to immunoblot analysis with an anti-Flag MAb and an anti-actin MAb (as a control). (B) At $24 \mathrm{~h}$ post-transfection, cells were fixed, permeabilized, and immunostained with an anti-Flag MAb followed by an Alexa 488-conjugated anti-mouse lgG antibody. Cells were analyzed by confocal laser scanning microscopy (Olympus FV1000). (C) At $48 \mathrm{~h}$ after transfection, cells were recovered and the activities of firefly and Renilla luciferases were measured in lysates. For each sample, the firefly luciferase activity (pGV-HL21) was normalized by reference to Renilla luciferase activity (pRL-SV40). (D) At $48 \mathrm{~h}$ post-transfection, cells were fixed and stained with propidium iodide for the analysis of DNA content. GFP-positive

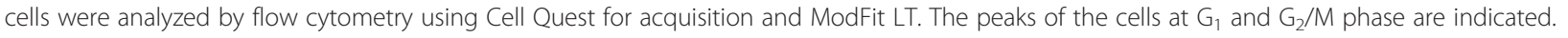
(E) At $48 \mathrm{~h}$ post-transfection, cells were collected, lysed, and analyzed for phosphorylation of Rb by immunoblotting with an anti-Rb MAb using an anti-actin MAb as a control. ppRb, hyperphosphorylated forms of Rb; pRb, hypo- and unphosphorylated forms of Rb. (F) At $48 \mathrm{~h}$ posttransfection, cells were collected, lysed, $\beta$-galactosidase activity was measured. Caspase-3 activity was measured in the cell lysates with an equal amount of $\beta$-galactosidase activity. Each of the columns and its associated error bar represent the mean \pm standard deviation (SD) of results from four different experiments. The asterisk $\left(^{*}\right)$ represents a $p$-value of $<0.01$. (G) At $48 \mathrm{~h}$ post-transfection, cells were stained with PE-Annexin $V$ and 7-AAD to identify apoptotic cells. GFP was used as a reporter to discriminate between transfected and untransfected cells. The percentage of Annexin V-positive and 7-AAD-negative cells relative to GFP-positive cells indicates the level of apoptosis. 
marker plasmid. The histograms show representative data from one of three independent experiments. As shown in Figure 1D, flow cytometry analysis revealed that there was a marked increase in the percentage of cells in the $G_{1}$ phase in cells transfected with Tax (approximately $92 \% \pm 4.5 \%)$ compared with cells transfected with the control vector (approximately $58 \% \pm 4.3 \%$ ), strongly indicating that $G_{1}$ cell cycle arrest was induced in Tax-expressing cells ( $\mathrm{p}<0.001)$. To confirm this result, total cell extracts were collected $48 \mathrm{~h}$ post-transfection and the phosphorylation status of $\mathrm{Rb}$ was determined by immunoblotting with an anti- $\mathrm{Rb}$ MAb, which detects all forms of $\mathrm{Rb}$. The phosphorylation status of $\mathrm{Rb}$ serves as a marker of cells in the $G_{0} / G_{1}$ phase of the cell cycle, since $R b$ is progressively phosphorylated throughout the $\mathrm{G}_{1}$ phase and is hyperphosphorylated upon transition into the $S$ phase [35]. As shown in Figure 1E, hyperphosphorylated form (ppRb) migrated more slowly than the hypo- and unphosphorylated forms ( $\mathrm{pRb})$. The majority of $\mathrm{Rb}$ was hyperphosphorylated (upper major band) in cells transfected with the control vector; however, a decrease in the level of hyperphosphorylated form ( $\mathrm{ppRb}$ ) and an increase in the levels of hypo- and/or unphosphorylated form ( $\mathrm{pRb}$ ) were observed in extracts prepared from Tax-expressing cells. These results confirmed that Tax prevents hyperphosphorylation of $\mathrm{Rb}$ and blocks cell cycle progression at the $\mathrm{G}_{1}$ phase.

To analyze whether Tax induced apoptosis, HeLa cells were transfected with a Tax expression vector or a control vector, and the activity of caspase-3, which plays an essential role in apoptosis, was measured. Caspase- 3 activity was significantly higher in Tax-expressing cells than in control cells (Figure 1F; $\mathrm{p}<0.01$ ). Next, the apoptotic activity of Tax was further quantified using flow cytometry by co-staining transfected cells with phycoerythrin (PE)-Annexin $\mathrm{V}$ and 7-amino-actinomycin $\mathrm{D}$ (7-AAD) (Figure 1G). A prominent event in early apoptosis is the exposure of phosphatidylserine (PS) on the outer leaflet of the cell membrane. Cell surfaceexposed PS is specifically detected by PE-Annexin V, and during the late stages of apoptosis or necrosis, cell membrane integrity is lost, allowing entry of the DNAbinding dye 7-AAD. The population of Annexin Vpositive and 7-AAD-negative apoptotic cells was much higher in Tax-expressing cells (19.9\%) than in cells transfected with the control vector (3.5\%). Because the same trends were observed for caspase- 3 activity (Figure 1F) and apoptotic activity (Figure 1G), it was concluded that Tax induces apoptosis in HeLa cells.

\section{Large-scale expression profiling of cellular genes after transfection with tax}

To analyze the mechanism(s) underlying the regulation of cell cycle progression and apoptosis by Tax, total
RNA was isolated from HeLa cells transfected with Tax or a control vector, and each RNA sample was subjected to microarray analysis (GEO accession number GSE34750). Data sets were analyzed using GeneSpring GX 11.0 software for gene expression, clustering, gene ontology, and significant signaling pathways. Using microarrays containing approximately 18,400 mRNA transcripts, 342 genes were identified (269 upregulated and 73 downregulated) that showed statistically significant levels of differential regulation by $\operatorname{Tax}(\mathrm{p}<0.05)$ (Tables 1 and 2).

The upregulated genes (2-fold or greater) were clustered within functional groups involved in transcription/ translation/RNA processing, signal transduction, the immune response, apoptosis, cell cycle regulation, and cell growth/proliferation (Table 1 ). In addition, a number of molecules involved in the immune response were significantly downregulated by Tax (Table 2).

\section{Tax induces the expression of genes related to cell cycle progression and apoptosis}

It was hypothesized that changes in gene expression may provide valuable information about the dysregulation of cell cycle progression induced by Tax and about how Tax might affect the genes relevant to this process. As shown in Figure 2A, of 17 genes related to cell cycle progression that were regulated by Tax, five were downregulated and 12 were upregulated (fold change $>2.0$; $\mathrm{p}<0.05)$. Genes associated with mitosis (CENPF, SEP11, and NF2), including the mitotic cell cycle checkpoint (MAD2L1) and mitotic centrosome separation (KIF11), were repressed by Tax. By contrast, genes upregulated by Tax were functionally classified as genes related to the cell cycle (GADD45A, RGS2, MAP3K8, SESN1, CDKN1A, CYLD, PLK2, SMAD3, JUN, GADD45B, DUSP1 and IL8). Many of these genes are also involved in other processes, such as the response to stress (GADD45B), the response to DNA damage (GADD45A, SESN1, CDKN1A), MAP kinase activity (GADD45B, MAP3K8, DUSP1), cell proliferation (JUN and IL8), and negative regulation of the cell cycle (CYLD, PLK2 and SMAD3). Genes such as SMAD3, GADD45B, and DUSP1 were also identified as having a role in apoptosis, and IL8 is additionally involved in inflammation and the immune response.

The microarray results for genes related to cell cycle progression were validated by performing real-time quantitative reverse transcription polymerase chain reaction (qRT-PCR) on five upregulated genes (Figure 2B). The results of the qRT-PCR agreed with those obtained by microarray analysis.

Next, Tax-regulated genes related to apoptosis were identified (Figure 2C). The microarray results revealed that 21 pro- or anti-apoptotic genes were regulated by 
Table 1 Genes upregulated by Tax (fold change $\geq 2.0, p<0.05$ )

\begin{tabular}{|c|c|c|c|}
\hline Gene symbol & Gene description & Gene ID & Fold change \\
\hline & Transcription/Translation/RNA processing & & \\
\hline FOXF1 & forkhead box F1 & 2294 & 2.0 \\
\hline NFKB2 & nuclear factor of kappa light polypeptide gene enhancer in B-cells 2 (p49/p100) & 4791 & 2.0 \\
\hline NR6A1 & nuclear receptor subfamily 6, group A, member 1 & 2649 & 2.0 \\
\hline CEBPD & CCAAT/enhancer binding protein (C/EBP), delta & 1052 & 2.1 \\
\hline ETV5 & ets variant 5 & 2119 & 2.1 \\
\hline FST & follistatin & 10468 & 2.2 \\
\hline KLF6 & Kruppel-like factor 6 & 1316 & 2.2 \\
\hline CEBPD & CCAAT/enhancer binding protein (C/EBP), delta & 1052 & 2.3 \\
\hline EGR3 & early growth response 3 & 1960 & 2.3 \\
\hline SAMD4A & sterile alpha motif domain containing $4 \mathrm{~A}$ & 23034 & 2.3 \\
\hline ELL2 & elongation factor, RNA polymerase II, 2 & 22936 & 2.4 \\
\hline HIVEP2 & human immunodeficiency virus type I enhancer binding protein 2 & 3097 & 2.4 \\
\hline MAFB & v-maf musculoaponeurotic fibrosarcoma oncogene homolog B (avian) & 9935 & 2.4 \\
\hline FOSL2 & FOS-like antigen 2 & 2355 & 2.5 \\
\hline ID2 & inhibitor of DNA binding 2, dominant negative helix-loop-helix protein & 3398 & 2.5 \\
\hline KLF2 & Kruppel-like factor 2 (lung) & 10365 & 2.5 \\
\hline RELB & v-rel reticuloendotheliosis viral oncogene homolog B & 5971 & 2.5 \\
\hline MAFF & v-maf musculoaponeurotic fibrosarcoma oncogene homolog F (avian) & 23764 & 2.8 \\
\hline LARP6 & La ribonucleoprotein domain family, member 6 & 55323 & 3.1 \\
\hline REL & v-rel reticuloendotheliosis viral oncogene homolog (avian) & 5966 & 3.1 \\
\hline FOSB & FBJ murine osteosarcoma viral oncogene homolog B & 2354 & 3.2 \\
\hline HES1 & hairy and enhancer of split 1 (Drosophila) & 3280 & 3.2 \\
\hline SOD2 & superoxide dismutase 2 , mitochondrial & 6648 & 3.4 \\
\hline ATF3 & activating transcription factor 3 & 467 & 3.6 \\
\hline FOSL1 & FOS-like antigen 1 & 8061 & 4.1 \\
\hline ZFP36 & zinc finger protein 36, C3H type, homolog (mouse) & 7538 & 4.2 \\
\hline ZNF331 & zinc finger protein 331 & 55422 & 4.4 \\
\hline $\mathrm{BACH} 2$ & BTB and CNC homology 1, basic leucine zipper transcription factor 2 & 60468 & 4.4 \\
\hline NFKBIE & nuclear factor of kappa light polypeptide gene enhancer in B-cells inhibitor, epsilon & 4794 & 4.4 \\
\hline EGR1 & early growth response 1 & 1958 & 6.2 \\
\hline FOS & FBJ murine osteosarcoma viral oncogene homolog & 2353 & 8.4 \\
\hline \multirow[t]{2}{*}{ NR4A2 } & nuclear receptor subfamily 4, group A, member 2 & 4929 & 10.9 \\
\hline & Signal Transduction & & \\
\hline EDN2 & endothelin 2 & 1907 & 2.0 \\
\hline EPHA2 & $\mathrm{EPH}$ receptor $\mathrm{A} 2$ & 1969 & 2.1 \\
\hline RIT1 & Ras-like without CAAX 1 & 6016 & 2.1 \\
\hline SH2D3A & SH2 domain containing $3 \mathrm{~A}$ & 10045 & 2.1 \\
\hline KLRC1 & killer cell lectin-like receptor subfamily C, member $1 / / /$ killer cell lectin-like receptor subfamily $C$, member 2 & 3821 & 2.2 \\
\hline PSD4 & pleckstrin and Sec7 domain containing 4 & 23550 & 2.5 \\
\hline ADM & adrenomedullin & 133 & 2.7 \\
\hline GPRC5C & G-protein-coupled receptor, family C, group 5, member C & 55890 & 2.7 \\
\hline BDKRB2 & bradykinin receptor B2 & 624 & 2.8 \\
\hline GDF15 & growth differentiation factor 15 & 9518 & 3.0 \\
\hline
\end{tabular}


Table 1 Genes upregulated by Tax (fold change $\geq \mathbf{2 . 0}, \mathbf{p}<\mathbf{0 . 0 5}$ ) (Continued)

\begin{tabular}{|c|c|c|c|}
\hline GPR87 & G protein-coupled receptor 87 & 53836 & 3.4 \\
\hline RASA4 & RAS p21 protein activator 4///RAS p21 protein activator 4 pseudogene & 10156 & 8.8 \\
\hline GEM & GTP binding protein overexpressed in skeletal muscle & 2669 & 14.1 \\
\hline GABBR1 & gamma-aminobutyric acid (GABA) B receptor, 1///ubiquitin D & 10537 & 24.5 \\
\hline \multirow[t]{2}{*}{ RRAD } & Ras-related associated with diabetes & 6236 & 115.2 \\
\hline & Inflammatory response/Immune response & & \\
\hline KLRC1 & killer cell lectin-like receptor subfamily C, member 1 & 3821 & 2.2 \\
\hline PTGS2 & prostaglandin-endoperoxide synthase 2 (prostaglandin G/H synthase and cyclooxygenase) & 5743 & 2.3 \\
\hline CCL22 & chemokine (C-C motif) ligand 22 & 6367 & 3.0 \\
\hline IL6R & interleukin 6 receptor & 3570 & 3.0 \\
\hline TNIP1 & TNFAIP3 interacting protein 1 & 10318 & 3.2 \\
\hline $\mathrm{EBI} 3$ & Epstein-Barr virus induced 3 & 10148 & 3.2 \\
\hline IL27RA & interleukin 27 receptor, alpha & 9466 & 3.5 \\
\hline TRIM22 & tripartite motif-containing 22 & 10346 & 3.8 \\
\hline IL32 & interleukin 32 & 9235 & 3.8 \\
\hline TNFAIP6 & tumor necrosis factor, alpha-induced protein 6 & 7130 & 4.0 \\
\hline GBP2 & guanylate binding protein 2 , interferon-inducible & 2634 & 5.2 \\
\hline GBP2 & guanylate binding protein 2, interferon-inducible & 2634 & 5.4 \\
\hline CCL19 & chemokine (C-C motif) ligand 19 & 6363 & 6.2 \\
\hline CXCL1 & chemokine (C-X-C motif) ligand 1 (melanoma growth stimulating activity, alpha) & 2919 & 11.7 \\
\hline CXCL11 & chemokine (C-X-C motif) ligand 11 & 6373 & 13.1 \\
\hline $\mathrm{CXCL3}$ & chemokine (C-X-C motif) ligand 3 & 2921 & 19.1 \\
\hline CCL20 & chemokine (C-C motif) ligand 20 & 6364 & 20.1 \\
\hline PTX3 & pentraxin-related gene, rapidly induced by IL-1 beta & 5806 & 81.1 \\
\hline \multirow[t]{2}{*}{ CXCL2 } & chemokine (C-X-C motif) ligand 2 & 2920 & 87.0 \\
\hline & Apoptosis regulation & & \\
\hline ZMAT3 & zinc finger, matrin type 3 & 64393 & 2.0 \\
\hline JMJD6 & jumonji domain containing 6 & 23210 & 2.0 \\
\hline AEN & apoptosis enhancing nuclease & 64782 & 2.1 \\
\hline ADORA2A & adenosine A2a receptor & 135 & 2.2 \\
\hline CD70 & CD70 molecule & 970 & 2.2 \\
\hline FAS & Fas (TNF receptor superfamily, member 6) & 355 & 2.3 \\
\hline BAG3 & BCL2-associated athanogene 3 & 9531 & 2.4 \\
\hline BIK & BCL2-interacting killer (apoptosis-inducing) & 638 & 2.4 \\
\hline BCL6 & B-cell CLL/lymphoma 6 & 604 & 2.7 \\
\hline TNFRSF1B & tumor necrosis factor receptor superfamily, member 1B & 7133 & 3.3 \\
\hline ZC $3 \mathrm{H} 12 \mathrm{~A}$ & zinc finger $\mathrm{CCCH}$-type containing 12A & 80149 & 4.1 \\
\hline NFKBIA & nuclear factor of kappa light polypeptide gene enhancer in B-cells inhibitor, alpha & 4792 & 5.2 \\
\hline NR4A1 & nuclear receptor subfamily 4, group A, member 1 & 3164 & 5.4 \\
\hline IER3 & immediate early response 3 & 8870 & 5.7 \\
\hline TNFAIP3 & tumor necrosis factor, alpha-induced protein 3 & 7128 & 6.4 \\
\hline BTG2 & BTG family, member 2 & 7832 & 7.0 \\
\hline TNFRSF9 & tumor necrosis factor receptor superfamily, member 9 & 3604 & 8.2 \\
\hline $\mathrm{BIRC} 3$ & baculoviral IAP repeat-containing 3 & 330 & 14.8 \\
\hline IL6 & interleukin 6 (interferon, beta 2) & 3569 & 18.0 \\
\hline
\end{tabular}


Table 1 Genes upregulated by Tax (fold change $\geq \mathbf{2 . 0}, \mathbf{p}<\mathbf{0 . 0 5}$ ) (Continued)

\begin{tabular}{|c|c|c|c|}
\hline & Cell cycle regulation & & \\
\hline GADD45A & growth arrest and DNA-damage-inducible, alpha & 1647 & 2.2 \\
\hline RGS2 & regulator of G-protein signaling 2, $24 \mathrm{kDa}$ & 5997 & 2.2 \\
\hline MAP3K8 & mitogen-activated protein kinase kinase kinase 8 & 1326 & 2.3 \\
\hline SESN1 & sestrin 1 & 27244 & 2.6 \\
\hline CDKN1A & cyclin-dependent kinase inhibitor 1A (p21, Cip1) & 1026 & 2.8 \\
\hline CYLD & cylindromatosis (turban tumor syndrome) & 1540 & 2.9 \\
\hline PLK2 & polo-like kinase 2 (Drosophila) & 10769 & 3.0 \\
\hline SMAD3 & SMAD family member 3 & 4088 & 4.4 \\
\hline JUN & jun oncogene & 3725 & 4.6 \\
\hline GADD45B & growth arrest and DNA-damage-inducible, beta & 4616 & 4.8 \\
\hline DUSP1 & dual specificity phosphatase 1 & 1843 & 8.5 \\
\hline \multirow[t]{2}{*}{ IL8 } & interleukin 8 & 3576 & 41.7 \\
\hline & Regulation of cell growth/Regulation of cell proliferation & & \\
\hline ZMAT3 & zinc finger, matrin type 3 & 64393 & 2.0 \\
\hline CSF1 & colony stimulating factor 1 (macrophage) & 1435 & 2.1 \\
\hline FGFR2 & fibroblast growth factor receptor 2 & 2263 & 2.1 \\
\hline ABTB2 & ankyrin repeat and BTB (POZ) domain containing 2 & 25841 & 2.4 \\
\hline sOCS2 & suppressor of cytokine signaling 2 & 8835 & 2.4 \\
\hline PGF & placental growth factor & 5228 & 2.6 \\
\hline HBEGF & heparin-binding EGF-like growth factor & 1839 & 2.7 \\
\hline LIF & leukemia inhibitory factor (cholinergic differentiation factor) & 3976 & 2.9 \\
\hline FGF18 & fibroblast growth factor 18 & 8817 & 4.9 \\
\hline CCL2 & chemokine (C-C motif) ligand 2 & 6347 & 6.7 \\
\hline IL11 & interleukin 11 & 3589 & 7.4 \\
\hline RARRES1 & retinoic acid receptor responder (tazarotene induced) 1 & 5918 & 7.5 \\
\hline IGFBP1 & insulin-like growth factor binding protein 1 & 3484 & 32.2 \\
\hline DLGAP4 & discs, large (Drosophila) homolog-associated protein 4 & 22839 & 2.5 \\
\hline EFNA1 & ephrin-A1 & 1942 & 2.5 \\
\hline \multirow[t]{2}{*}{ WNT4 } & wingless-type MMTV integration site family, member 4 & 54361 & 9.3 \\
\hline & Cell adhesion & & \\
\hline LYPD3 & LY6/PLAUR domain containing 3 & 27076 & 2.0 \\
\hline PDZD2 & PDZ domain containing 2 & 23037 & 2.1 \\
\hline FERMT2 & fermitin family homolog 2 (Drosophila) & 10979 & 2.2 \\
\hline NINJ1 & ninjurin 1 & 4814 & 2.2 \\
\hline SIRPA & signal-regulatory protein alpha & 140885 & 2.2 \\
\hline COL7A1 & collagen, type VII, alpha 1 & 1294 & 2.3 \\
\hline LAMB3 & laminin, beta 3 & 3914 & 2.6 \\
\hline $\mathrm{CDH} 5$ & cadherin 5, type 2 (vascular endothelium) & 1003 & 4.4 \\
\hline CTGF & connective tissue growth factor & 1490 & 4.4 \\
\hline SAA1 & serum amyloid $\mathrm{A} 1 / / /$ serum amyloid $\mathrm{A} 2$ & 6288 & 10.3 \\
\hline \multirow[t]{2}{*}{ ICAM1 } & intercellular adhesion molecule 1 & 3383 & 10.8 \\
\hline & Transport & & \\
\hline SLC37A1 & solute carrier family 37 (glycerol-3-phosphate transporter), member 1 & 54020 & 2.0 \\
\hline SLC1A3 & solute carrier family 1 (glial high affinity glutamate transporter), member 3 & 6507 & 2.2 \\
\hline
\end{tabular}


Table 1 Genes upregulated by Tax (fold change $\geq \mathbf{2 . 0}, \mathbf{p}<\mathbf{0 . 0 5}$ ) (Continued)

\begin{tabular}{|c|c|c|c|}
\hline C19orf28 & chromosome 19 open reading frame 28 & 126321 & 2.6 \\
\hline NPTX1 & neuronal pentraxin I & 4884 & 2.6 \\
\hline SLC2A6 & solute carrier family 2 (facilitated glucose transporter), member 6 & 11182 & 3.5 \\
\hline \multirow[t]{2}{*}{ HBA1 } & hemoglobin, alpha 1 & 3039 & 5.4 \\
\hline & Metabolic process & & \\
\hline HMGCS1 & 3-hydroxy-3-methylglutaryl-Coenzyme A synthase 1 (soluble) & 3157 & 2.0 \\
\hline PTGS1 & prostaglandin-endoperoxide synthase 1 (prostaglandin G/H synthase and cyclooxygenase) & 5742 & 2.0 \\
\hline IDS & iduronate 2-sulfatase & 3423 & 2.2 \\
\hline PI4K2A & phosphatidylinositol 4-kinase type 2 alpha & 55361 & 2.2 \\
\hline PLA2G4C & phospholipase A2, group IVC (cytosolic, calcium-independent) & 8605 & 2.2 \\
\hline C12orf5 & chromosome 12 open reading frame 5 & 57103 & 2.3 \\
\hline PANX1 & pannexin 1 & 24145 & 2.3 \\
\hline ABCA1 & ATP-binding cassette, subfamily A (ABC1), member 1 & 19 & 2.4 \\
\hline AMPD3 & adenosine monophosphate deaminase (isoform E) & 272 & 2.4 \\
\hline SAT1 & spermidine/spermine N1-acetyltransferase 1 & 6303 & 2.5 \\
\hline AKR1B1 & aldo-keto reductase family 1 , member B1 (aldose reductase) & 231 & 2.6 \\
\hline GCNT3 & glucosaminyl (N-acetyl) transferase 3, mucin type & 9245 & 2.6 \\
\hline PITPNM1 & phosphatidylinositol transfer protein, membrane-associated 1 & 9600 & 2.6 \\
\hline MICAL2 & microtubule-associated monoxygenase, calponin and LIM domain containing 2 & 9645 & 3.2 \\
\hline PPAP2B & phosphatidic acid phosphatase type $2 \mathrm{~B}$ & 8613 & 3.2 \\
\hline ARG2 & arginase, type II & 384 & 4.1 \\
\hline PTGES & prostaglandin E synthase & 9536 & 4.7 \\
\hline \multirow[t]{2}{*}{ GFPT2 } & glutamine-fructose-6-phosphate transaminase 2 & 9945 & 5.0 \\
\hline & Phosphorylation/Dephosphorylation & & \\
\hline DUSP6 & dual specificity phosphatase 6 & 1848 & 2.0 \\
\hline FAM129A & family with sequence similarity 129 , member A & 116496 & 2.3 \\
\hline DUSP13 & dual specificity phosphatase 13 & 51207 & 2.6 \\
\hline DUSP5 & dual specificity phosphatase 5 & 1847 & 4.1 \\
\hline \multirow[t]{2}{*}{ PTPRE } & protein tyrosine phosphatase, receptor type, E & 5791 & 4.1 \\
\hline & Response to stress & & \\
\hline HSPA2 & heat shock $70 \mathrm{kDa}$ protein 2 & 3306 & 2.3 \\
\hline HSPA1A & heat shock $70 \mathrm{kDa}$ protein $1 \mathrm{~A}$ & 3303 & 2.9 \\
\hline HSPB8 & heat shock 22 kDa protein 8 & 26353 & 3.1 \\
\hline HSPB3 & heat shock $27 \mathrm{kDa}$ protein 3 & 8988 & 4.0 \\
\hline HSPB7 & heat shock 27 kDa protein family, member 7 (cardiovascular) & 27129 & 4.0 \\
\hline DNAJB1 & DnaJ (Hsp40) homolog, subfamily B, member 1 & 3337 & 4.2 \\
\hline \multirow[t]{2}{*}{ HSPA6 } & heat shock $70 \mathrm{kDa}$ protein 6 & 3310 & 7.6 \\
\hline & Ubiquitin & & \\
\hline ENC1 & ectodermal-neural cortex (with BTB-like domain) & 8507 & 2.3 \\
\hline \multirow[t]{2}{*}{ MAP1LC3C } & microtubule-associated protein 1 light chain 3 gamma & 440738 & 3.4 \\
\hline & Others/Unknown & & \\
\hline OLR1 & oxidized low density lipoprotein (lectin-like) receptor 1 & 4973 & 2.0 \\
\hline TRIB1 & tribbles homolog 1 (Drosophila) & 10221 & 2.0 \\
\hline UNC13A & unc-13 homolog A (C. elegans) & 23025 & 2.0 \\
\hline SNAl1 & snail homolog 1 (Drosophila) & 6615 & 2.1 \\
\hline
\end{tabular}


Table 1 Genes upregulated by Tax (fold change $\geq \mathbf{2 . 0}, \mathbf{p}<\mathbf{0 . 0 5}$ ) (Continued)

\begin{tabular}{|c|c|c|c|}
\hline FSTL3 & follistatin-like 3 (secreted glycoprotein) & 10272 & 2.2 \\
\hline GAB2 & GRB2-associated binding protein 2 & 9846 & 2.2 \\
\hline PDLIM3 & PDZ and LIM domain 3 & 27295 & 2.2 \\
\hline PMEPA1 & prostate transmembrane protein, androgen induced 1 & 56937 & 2.2 \\
\hline SLC1A3 & solute carrier family 1 (glial high affinity glutamate transporter), member 3 & 6507 & 2.2 \\
\hline FNDC3B & fibronectin type III domain containing 3B & 64778 & 2.3 \\
\hline PHLDA3 & pleckstrin homology-like domain, family A, member 3 & 23612 & 2.3 \\
\hline SLC25A4 & solute carrier family 25 (mitochondrial carrier; adenine nucleotide translocator), member 4 & 291 & 2.3 \\
\hline TPM4 & tropomyosin 4 & 7171 & 2.3 \\
\hline DSE & dermatan sulfate epimerase & 29940 & 2.5 \\
\hline VEGFC & vascular endothelial growth factor $C$ & 7424 & 2.5 \\
\hline CSTA & cystatin A (stefin A) & 1475 & 2.6 \\
\hline $\mathrm{ZDHHC18}$ & zinc finger, DHHC-type containing 18 & 84243 & 2.6 \\
\hline CDK2AP2 & cyclin-dependent kinase 2 associated protein 2 & 10263 & 2.7 \\
\hline TIPARP & TCDD-inducible poly(ADP-ribose) polymerase & 25976 & 2.7 \\
\hline CSTA & cystatin A (stefin A) & 1475 & 2.8 \\
\hline TNFAIP2 & tumor necrosis factor, alpha-induced protein 2 & 7127 & 2.8 \\
\hline PSD4 & pleckstrin and Sec7 domain containing 4 & 23550 & 3.1 \\
\hline KRT17 & keratin 17 & 3872 & 3.7 \\
\hline ARC & activity-regulated cytoskeleton-associated protein & 23237 & 5.4 \\
\hline LXN & latexin & 56925 & 5.5 \\
\hline TRIM31 & tripartite motif-containing 31 & 11074 & 20.1 \\
\hline
\end{tabular}

Tax (fold change $>2.0 ; \mathrm{p}<0.05$ ). Two genes associated with the induction of apoptosis, CARD10 and BCLAF1, were downregulated by Tax. The majority of the genes upregulated by Tax were involved in apoptosis. Furthermore, several of these genes also function in the immune response (ADORA2A, CD70, FAS, BCL6, TNFRSF1B and IL6). Interestingly, several highly upregulated genes, such as IER3, TNFAIP3, BIRC3 and IL6, have both proand anti-apoptotic functions. In contrast, the highly upregulated gene, TNFRSF9, is pro-apoptotic only. TNF and TNF receptor family genes were also found to be upregulated by Tax in this study.

To confirm and extend the results of the microarray experiments, expression of the pro-apoptotic and antiapoptotic genes regulated by Tax was measured by qRTPCR using specific primers. Genes upregulated in the microarray were also upregulated in qRT-PCR (Figure 2D), although there were small differences in the levels measured by the two methods. For example, the expression levels of BIRC3 and IL6 measured by qRTPCR were almost twice that measured by microarray analysis, and the expression level of the apoptosis inductor TNFRSF9 was more than three times higher by qRT-PCR than by microarray. Despite these minor differences, overall gene expression levels measured by qRT-PCR were similar to those measured by microarray analysis.

Visualizing the spatiotemporal dynamics of the regulation of cell cycle progression and apoptosis by tax

To clarify whether Tax causes apoptosis independently of its ability to induce $G_{1}$ arrest, the spatiotemporal patterns of cell cycle regulation in response to Tax expression were monitored in HeLa/Fucci2 cells [33]. This system was chosen because it allows dual-color imaging, in which $G_{1}$-phase nuclei are labeled orange and $S / G_{2}$ / $M$-phase nuclei are labeled green. A fluorescent Tax vector was constructed that allows the identification of Tax-expressing HeLa/Fucci2 cells. This vector contained Tax, an internal ribosomal entry site (IRES), cyan fluorescent protein (CFP), and a Flag sequence at the 3' end of tax. The vector was expressed in HeLa cells, and Tax-expressing cells were stained with an anti-Flag MAb followed by an Alexa Fluor 594 secondary antibody (red). As shown in Figure 3A, all Tax-expressing cells were CFP-positive (blue).

HeLa/Fucci2 cells were plated on a glass coverslip, transiently transfected with Tax-IRES-CFP or the CFP 
Table 2 Genes downregulated by Tax (fold change $\geq \mathbf{2 . 0}, \mathbf{p}<\mathbf{0 . 0 5}$ )

\begin{tabular}{|c|c|c|c|}
\hline Gene symbol & Gene description & Gene ID & Fold change \\
\hline & Transcription/Translation/RNA processing & & \\
\hline ANP32A & Cerebellar leucine rich acidic nuclear protein (LANP) & 8125 & 2.0 \\
\hline EID1 & EP300 interacting inhibitor of differentiation 1 & 23741 & 2.0 \\
\hline PAIP1 & poly(A) binding protein interacting protein 1 & 10605 & 2.0 \\
\hline RBM4 & RNA binding motif protein 4 & 5936 & 2.0 \\
\hline SFRS7 & splicing factor, arginine/serine-rich 7, $35 \mathrm{kDa}$ & 6432 & 2.0 \\
\hline SR140 & U2-associated SR140 protein & 23350 & 2.0 \\
\hline BCLAF1 & BCL2-associated transcription factor 1 & 9774 & 2.1 \\
\hline IMPACT & Impact homolog (mouse) & 55364 & 2.3 \\
\hline LSM5 & LSM5 homolog, U6 small nuclear RNA associated (S. cerevisiae) & 23658 & 2.3 \\
\hline MRPS14 & mitochondrial ribosomal protein S14 & 63931 & 2.3 \\
\hline SUB1 & SUB1 homolog (S. cerevisiae) & 10923 & 2.3 \\
\hline ZNF623 & zinc finger protein 623 & 9831 & 2.3 \\
\hline BRIP1 & BRCA1 interacting protein C-terminal helicase 1 & 83990 & 2.4 \\
\hline \multirow[t]{2}{*}{ TTF2 } & transcription termination factor, RNA polymerase II & 8458 & 2.6 \\
\hline & Signal transduction & & \\
\hline PDE1A & phosphodiesterase 1A, calmodulin-dependent & 5136 & 2.0 \\
\hline PDE3A & phosphodiesterase 3A, cGMP-inhibited & 5139 & 2.0 \\
\hline $\mathrm{PRKCl}$ & protein kinase $C$, iota & 5584 & 2.1 \\
\hline \multirow[t]{2}{*}{ SRI } & sorcin & 6717 & 2.8 \\
\hline & Immune response/Response to virus & & \\
\hline DDX58 & DEAD (Asp-Glu-Ala-Asp) box polypeptide 58 & 23586 & 2.2 \\
\hline |F|44 & interferon-induced protein 44 & 10561 & 2.2 \\
\hline DDX60 & DEAD (Asp-Glu-Ala-Asp) box polypeptide 60 & 55601 & 3.0 \\
\hline IFIT3 & interferon-induced protein with tetratricopeptide repeats 3 & 3437 & 4.1 \\
\hline IFIT2 & interferon-induced protein with tetratricopeptide repeats 2 & 3433 & 4.4 \\
\hline IFIT1 & interferon-induced protein with tetratricopeptide repeats 1 & 3434 & 6.0 \\
\hline \multirow[t]{2}{*}{ OASL } & 2'-5'-oligoadenylate synthetase-like & 8638 & 6.4 \\
\hline & Apoptosis & & \\
\hline CARD10 & caspase recruitment domain family, member 10 & 29775 & 2.0 \\
\hline \multirow[t]{2}{*}{ BCLAF1 } & BCL2-associated transcription factor 1 & 9774 & 2.1 \\
\hline & Cell cycle & & \\
\hline MAD2L1 & MAD2 mitotic arrest deficient-like 1 (yeast) & 4085 & 2.0 \\
\hline KIF11 & kinesin family member 11 & 3832 & 2.1 \\
\hline NF2 & neurofibromin 2 (merlin) & 4771 & 2.1 \\
\hline SEP11 & septin 11 & 55752 & 2.1 \\
\hline \multirow[t]{2}{*}{ CENPF } & centromere protein F, 350/400 ka (mitosin) & 1063 & 2.5 \\
\hline & Regulation of cell proliferation & & \\
\hline BMP2 & bone morphogenetic protein 2 & 650 & 2.2 \\
\hline DAB2 & disabled homolog 2, mitogen-responsive phosphoprotein (Drosophila) & 1601 & 2.4 \\
\hline \multirow[t]{2}{*}{ FGF2 } & fibroblast growth factor 2 (basic) & 2247 & 3.4 \\
\hline & Cell signaling & & \\
\hline PCSK1 & proprotein convertase subtilisin/kexin type 1 & 5122 & 4.8 \\
\hline
\end{tabular}

\section{Cell adhesion}


Table 2 Genes downregulated by Tax (fold change $\geq \mathbf{2 . 0}, \mathbf{p}<\mathbf{0 . 0 5}$ ) (Continued)

\begin{tabular}{|c|c|c|c|}
\hline CD24 & CD24 molecule & 100133941 & 2.3 \\
\hline PKP2 & plakophilin 2 & 5318 & 2.3 \\
\hline \multirow[t]{2}{*}{ COL14A1 } & collagen, type XIV, alpha 1 & 7373 & 2.5 \\
\hline & Nucleosome assembly & & \\
\hline \multirow[t]{2}{*}{ H2AFV } & $\mathrm{H} 2 \mathrm{~A}$ histone family, member $\mathrm{V}$ & 94239 & 2.0 \\
\hline & Transport & & \\
\hline CNGB1 & cyclic nucleotide gated channel beta 1 & 1258 & 2.0 \\
\hline SCNN1A & sodium channel, nonvoltage-gated 1 alpha & 6337 & 2.0 \\
\hline ANO2 & anoctamin 2 & 57101 & 2.1 \\
\hline CHRNA9 & cholinergic receptor, nicotinic, alpha 9 & 55584 & 2.2 \\
\hline SORBS1 & sorbin and $\mathrm{SH} 3$ domain containing 1 & 10580 & 2.3 \\
\hline STEAP4 & STEAP family member 4 & 79689 & 2.3 \\
\hline \multirow[t]{2}{*}{ SRI } & sorcin & 6717 & 2.6 \\
\hline & Metabolic process & & \\
\hline \multirow[t]{2}{*}{ ACSL4 } & acyl-CoA synthetase long-chain family member 4 & 2182 & 2.0 \\
\hline & Ubiquitin & & \\
\hline $\mathrm{FBXO3}$ & F-box protein 3 & 26273 & 2.0 \\
\hline HERC6 & hect domain and RLD 6 & 55008 & 2.1 \\
\hline DZIP3 & DAZ interacting protein 3 , zinc finger & 9666 & 2.3 \\
\hline \multirow[t]{2}{*}{ HERC5 } & hect domain and RLD 5 & 51191 & 4.8 \\
\hline & Others/Unknown & & \\
\hline NIP7 & nuclear import 7 homolog (S. cerevisiae) & 51388 & 2.0 \\
\hline PPL & periplakin & 5493 & 2.0 \\
\hline ADK & adenosine kinase & 132 & 2.1 \\
\hline $\mathrm{DlO} 2$ & deiodinase, iodothyronine, type $\|$ & 1734 & 2.1 \\
\hline PICALM & phosphatidylinositol binding clathrin assembly protein & 8301 & 2.1 \\
\hline METAP2 & methionyl aminopeptidase 2 & 10988 & 2.2 \\
\hline HIP1R & huntingtin interacting protein 1 related & 9026 & 2.3 \\
\hline ERAP1 & KIAA0525 protein & 51752 & 2.4 \\
\hline DAB2 & disabled homolog 2, mitogen-responsive phosphoprotein (Drosophila) & 1601 & 2.5 \\
\hline
\end{tabular}

control vector, and then incubated for $24 \mathrm{~h}$. Next, fields containing orange, green, and blue fluorescence were selected and images were acquired using an Olympus LCV110 Imaging System (Figure 3B and 3C). The proliferation of control HeLa/Fucci2 cells was evidenced by the fraction of cells at $G_{1}$ phase with orange nuclei, the fraction of cells at $S / G_{2} / M$ phase with green nuclei, and the subsequent change in the fluorescence of these cells (Figure 3B upper panel and 3D), which indicated that the cells progressed normally through the cell cycle. At $24 \mathrm{~h}$ post-transfection, all HeLa/Fucci2 cells expressing Tax-IRES-CFP, which resulted in blue fluorescence, also had orange nuclei, indicating that they were in $G_{1}$ phase (Figure 3B, lower panel). During the culture period, HeLa/Fucci2 cells expressing Tax-IRES-CFP did not progress to $S / G_{2} / M$ phase, as evidenced by the presence of orange nuclei and the absence of green nuclei in Tax-expressing cells (Figure 3B). Additionally, a marked decrease was observed in the proportion of Tax-IRES-CFP-expressing cells in $S / G_{2} / M$ phase compared with control cells expressing CFP alone (Figure 3D), indicating that Tax arrests cells at the $G_{1}$ phase of the cell cycle.

Interestingly, overexpression of Tax appeared to reduce the number of HeLa/Fucci2 cells in culture (Figure 3E). Moreover, apoptosis was assessed by the appearance of rounded cells after an increase in the number of Tax-expressing cells at $\mathrm{G}_{1}$ phase, starting at $36 \mathrm{~h}$ post-transfection (Figure $3 \mathrm{~B}$ and $3 \mathrm{C}$ ). At $72 \mathrm{~h}$ post transfection, there was a notable reduction in the overall number of cells, as well as in the percentage of Taxexpressing cells (Figure $3 \mathrm{C}$ and $3 \mathrm{E}$ ). 

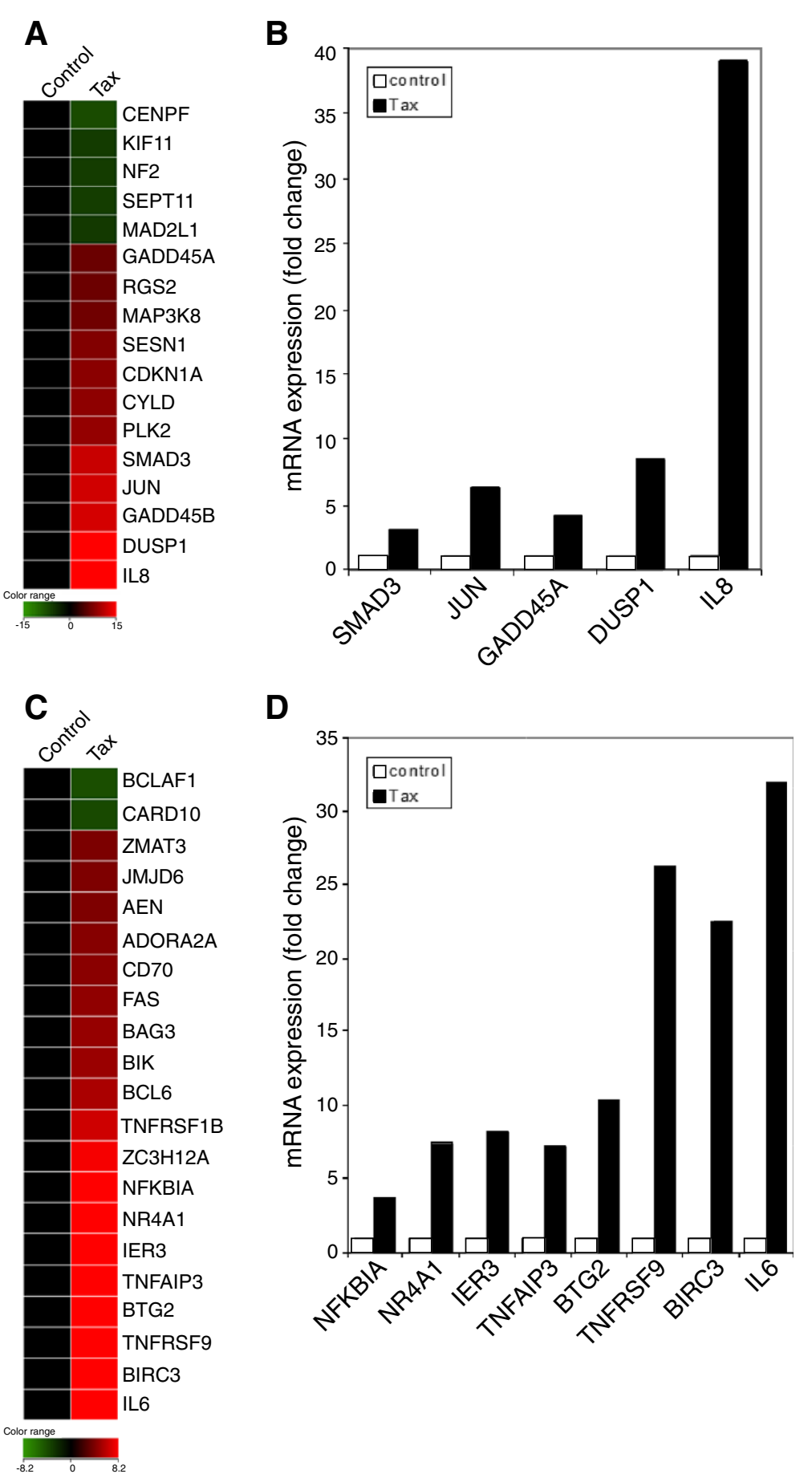

Figure 2 Expression profile of genes involved in cell cycle regulation and apoptosis that were altered following the induction of Tax protein. Heat maps showing the hierarchical clustering of genes involved in cell cycle regulation (A) and apoptosis (C) are shown for Tax-expressing cells. The color scheme indicates the fold change in gene expression, with upregulated genes shown in orange/red and downregulated genes shown in blue (with respect to baseline levels under control conditions (yellow)). qRT-PCR validation of the upregulated genes associated with cell cycle regulation (B) and apoptosis (D). RNA from Tax-expressing cells and control cells was used to validate the microarray data. The bars indicate the fold change in gene expression following Tax expression. Data were normalized to GAPDH mRNA. The results represent the mean of two samples from one experiment. 


\section{Expression kinetics of genes involved in cell cycle regulation and apoptosis that are altered following induction of tax protein}

To analyze the correlation between the expression of genes related to cell cycle regulation (IL8, SMAD3, CDKN1A, GADD45A and GADD45B) and apoptosis (IL6) (that are altered following the induction of Tax) with the dynamics of cell cycle and apoptosis (shown in Figure 3), total RNA was prepared at 12, 24, 36 and $48 \mathrm{~h}$ after transfection of HeLa cells with Tax or a control vector. Each RNA sample was then subjected to qRTPCR. As indicated in Figure 4, the expression levels of SMAD3, GADD45A and GADD45B in Tax-transfected cells began to increase from $6 \mathrm{~h}$ post-transfection and reached a peak at $24 \mathrm{~h}$, decreasing again by $36 \mathrm{~h}$. In the case of IL8, CDKN1A and IL6 in Tax-expressing cells, the expression levels reached a peak at $24 \mathrm{~h}$, decreased at $36 \mathrm{~h}$, and then increased again at $48 \mathrm{~h}$.

The kinetics and results from time-lapse imaging indicate that marked upregulation of IL8, SMAD3, CDKN1A, GADD45A, GADD45B and IL6 at 24 h posttransfection was well correlated with a notable reduction in the number of Tax-expressing cells and an increase of Tax-expressing cells in the $\mathrm{G}_{1}$ phase.

\section{Discussion}

This study used large-scale host cell gene profiling with human cDNA microarrays and time-lapse imaging of HeLa/Fucci2 cells to monitor the dynamics of Taxinduced cell death. Three major conclusions can be drawn from the data: (i) Tax induces cell cycle arrest at the $G_{1}$ phase in HeLa cells as assessed by flow cytometry. This result was confirmed by the accumulation of hypo- and/or unphosphorylated form of $\mathrm{Rb}$ in Taxexpressing cells. Moreover, analysis of Annexin Vstained cells and caspase- 3 activity clearly demonstrated that Tax promotes apoptosis. Thus, a high level of transiently-expressed Tax can arrest the cell cycle at the $\mathrm{G}_{1}$ phase and induce apoptosis in HeLa cells. (ii) The most interesting aspect of this study was visualizing the morphological dynamics of Tax-induced cell death after cell cycle arrest at the $G_{1}$ phase. Time-lapse imaging of HeLa/Fucci2 cells showed that Tax-induced apoptosis was dependent on the ability of Tax to induce $G_{1}$ arrest. (iii) Microarray data revealed that Tax induced gene expression changes in HeLa cells; 17 Tax-dependent genes were found to be related to cell cycle regulation and 23 to apoptosis (> 2.0-fold up- or downregulation). (iv) The kinetics of gene expression identified that Taxinduced changes in the expression of IL8, SMAD3, CDKN1A, GADD45A, GADD45B and IL6 closely correlated with the morphological changes of the cell cycle and apoptosis observed by time-lapse imaging. Since these genes are related not only to cell cycle regulation and apoptosis induction, but also to stress kinase pathways, the present study suggests that Tax may induce apoptosis and cell cycle arrest by activating genes related to stress-response signaling pathways.

Many studies show that the Tax oncoprotein accelerates G1 progression [3,4,7-12] and is capable of stimulating anti-apoptotic signaling pathways [29,30,36,37]. In contrast, the present study showed that Tax arrests cells at $G_{1}$, thereby inducing apoptosis. Our results consist with previous results obtained using HeLa cells and SupT1 cells $[20,38]$. There may be possible explanations for how Tax induces cell cycle arrest and apoptosis. One interesting finding from our microarray analysis was the marked activation of stress kinase pathways induced by Tax. In mammalian cells, two families of stressresponsive MAPKs, c-Jun N-terminal kinase (JNK) and p38, are activated by stimuli such as UV radiation, oxidative stress and translation inhibitors, as well as by inflammatory cytokines, tumor necrosis factor $\alpha$ (TNF $\alpha$ ), and transforming growth factor $\beta$ (TGF $\beta$ ). These signaling pathways promote apoptosis, cell survival, cell cycle arrest, inflammation and differentiation [39,40]. Interestingly, microarray analysis revealed that genes such as SMAD3 and SMAD4, which are the principal intracellular effectors of the TGF $\beta$ family $[41,42]$; GADD45A and GADD45B, which are implicated as stress sensors and activated by TGF $\beta$ in a SMADdependent manner [43-45]; DUSP1, DUSP5, DUSP6 and DUSP13, which are stress-inducible MAP kinase phosphatases [46]; MAP kinase kinase kinase 8 (MAP3K8) [46]; JUN [46], which is the effector transcription factor of the JNK pathway; and IL6, IL8 and FAS, which are inflammatory cytokines, were all upregulated by Tax. These genes, expressed in response to Tax, are mediators of JNK and p38 activity. In addition, we found that the kinetics of altered expression of several genes related to pathways involving stress-responsive MAPKs were closely correlated with the kinetics of the spatial and temporal patterns of cell cycle dynamics analyzed in time-lapse imaging. At $24 \mathrm{~h}$ post-transfection with Tax expression vectors, the genes for IL8, SMAD3, CDKN1A, GADD45A, GADD45B and IL6 were significantly upregulated (Figure 4) and the number of Tax-IRES-CFP-expressing cells were in $G_{1}$ phase and underwent apoptosis started to increase at same timing (Figure 3). Thus, the present results suggest that Tax may induce apoptosis and cell cycle arrest by activating several genes related to stress-response signaling pathways. This is supported by a recent publication showing that Tax, along with the activation of a stress kinase, can induce cell death [31]. Furthermore, the present findings consist with those observed by previous microarray analysis studies of HTLV-1-infected T cells, which demonstrated that HTLV-1 infection upregulated JNK activation kinase 1, 




B
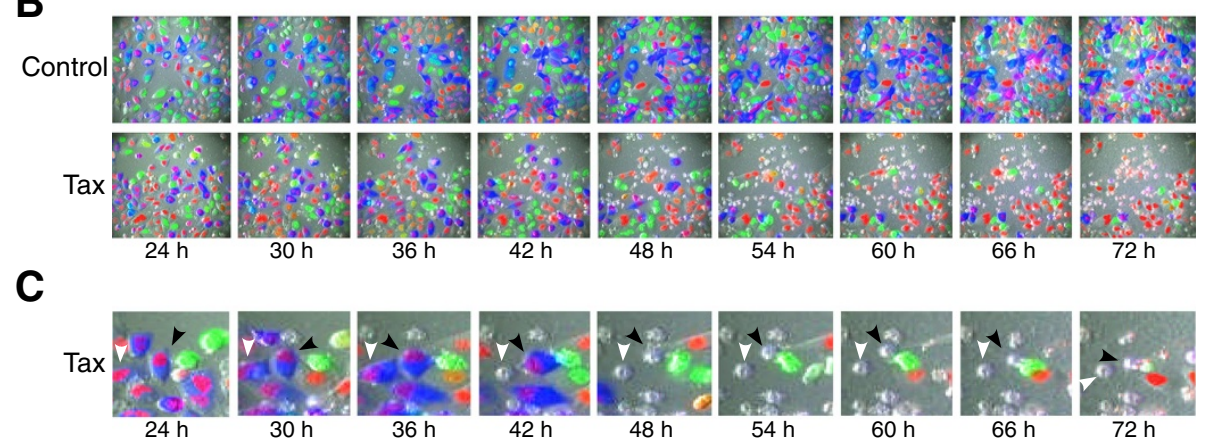

D

E
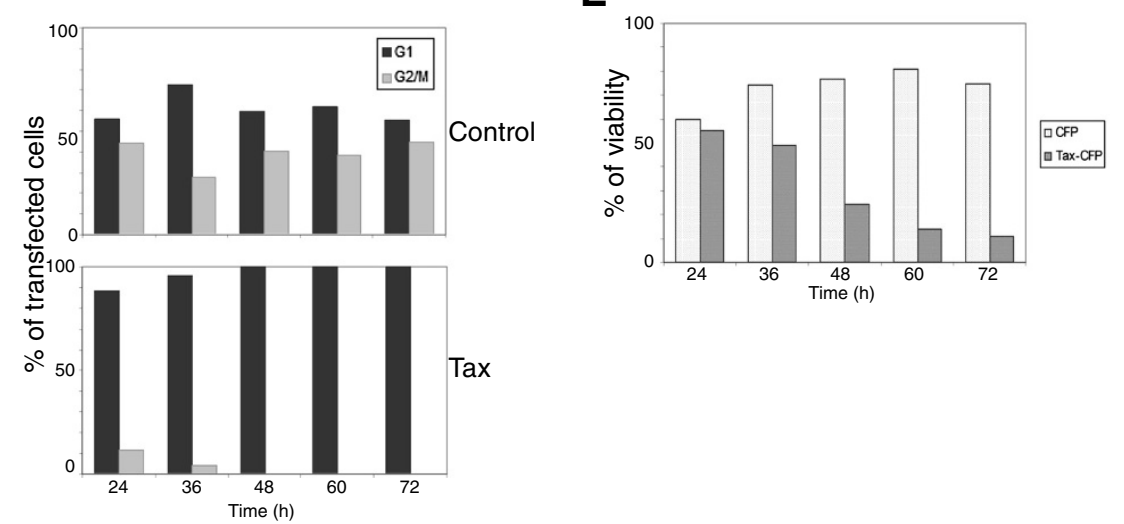

Figure 3 Time-lapse imaging of morphological changes in HeLa/Fucci2 cells after Tax-induced cell cycle arrest at $\mathrm{G}_{1}$ phase. (A) HeLa cells were transfected with the PCAGGS-Tax-IRES-CFP vector or the control PCAGGS-IRES-CFP vector. At $24 \mathrm{~h}$ after transfection, cells were stained with an anti-Flag MAb followed by an Alexa Fluor 594-conjugated secondary MAb and analyzed by confocal laser scanning microscopy (Olympus FV1000). Cells showing red and blue fluorescence express Tax-Flag and CFP, respectively. (B and C) HeLa/Fucci2 cells were transfected with the CAGGS-Tax-IRES-CFP vector or the control PCAGGS-IRES-CFP vector and monitored by time-lapse photography using the Olympus LCV110 Imaging System. One day after transfection, CFP-positive cells were selected and fluorescence and phase images were captured once every 15 min for 2 days. Cells showing orange or green fluorescence are in the $G_{1}$ or $S / G_{2} / M$ phase of cell cycle, respectively. Apoptotic cells, which show a rounded morphology, are marked by arrows. The populations of CFP-expressing cells at the $G_{1}$ and $S / G_{2} / M$ phases (D and $\mathbf{E}$, respectively) were quantified using MetaMorph 7.7.4 software.

GADD45 and the inflammatory cytokine, IL1 $\beta$, which are involved in MAPK stress-response pathways [23]. Recently, HTLV-1 Tax appeared indirectly to connect to cell cycle proteins such as SMAD3, SMAD4, GADD45A and GADD45B [47].

Our microarray analysis results identified one of the genes upregulated by Tax as CDKN1A, which codes p21 ${ }^{\mathrm{CIP1} / \mathrm{WAF} 1}$, known as Cdk inhibitor 1 . Again, this is in agreement with results from other microarray analyses showing that HTLV-1 infection and Tax expression upregulated $\mathrm{p} 21^{\mathrm{CIP} 1 / \mathrm{WAF} 1}$ in HTLV-1-infected $\mathrm{T}$ cells
[23] and the human Jurkat T-cell line JPX-9, which express Tax under the control of an inducible promoter [48]. Likewise, Tax has previously been shown to dramatically upregulate $\mathrm{p} 21^{\mathrm{CIP} 1 / \mathrm{WAF} 1} \mathrm{mRNA}$ transcription and stabilization of $\mathrm{p} 21^{\mathrm{CIP} 1 / \mathrm{WAF} 1}$ in HeLa cells $[20,21]$. Interestingly, only minimal p21/WAF1 promoter activity appears to be induced by Tax [23]. It is also known that basal levels of $\mathrm{p} 21^{\mathrm{CIP1} / \mathrm{WAF} 1}$ are required to promote TGF $\beta$-mediated cell cycle arrest, whereas a lack of $\mathrm{p} 21^{\mathrm{CIP} 1 / \mathrm{WAF} 1}$ allows the induction of cell proliferation in response to TGF $\beta$ [49]. Indeed, the loss of $221^{\mathrm{CIP} 1 / \mathrm{WAF} 1}$ 
Figure 4 Expression kinetics of genes involved in cell cycle regulation and apoptosis that were altered following induction of Tax. HeLa cells were transiently transfected with a pCAGGS-Tax Flag-tagged vector or the control pCAGGS vector. Total RNA was prepared at 12,24, 36 and $48 \mathrm{~h}$ after transfection and then each RNA sample was subjected to qRT-PCR. The bars indicate the fold change in the gene following Tax expression. Data were normalized to GAPDH mRNA. The results represent the mean \pm standard deviation (SD) of three samples from one experiment.

and $\mathrm{p} 27^{\mathrm{KIP} 1}$ from HOS cells apparently allows HTLV-1and Tax-induced G1 arrest to be bypassed [20]. Therefore, Tax may induce cell cycle arrest and apoptosis in HeLa cells by up-regulating GADD45B, SMAD3 and SMAD4 (which act downstream of TGF $\beta$ ) in the presence of $\mathrm{p} 21^{\mathrm{CIP} 1 / \mathrm{WAF} 1}$ (which is activated by Tax).

In HTLV-1 infected T cell lines, upregulated p21 CIP1/WAF1 may potentially function as an assembly factor for the cyclin D2/cdk4 complex, and the p21/cyclin D2/cdk4 complex may not act as an inhibitory complex but instead may allow the increased phosphorylation of $\mathrm{Rb}$ and accelerated progression into $S$ phase [50]. In the present study, Tax-mediated G1 arrest occurred in human papilloma virus type 18 (HPV-18)-transformed $\mathrm{HeLa}$ cells, in which the Rb pathway was activated by repression of HPV-18 E7 [51]. Indeed, in cells transfected with the control vector, the majority of $\mathrm{Rb}$ was in the hyperphosphorylated form ppRb (Figure 1E). By contrast, an accumulation of hypo- and/or unphosphorylated form pRb was observed in Tax-expressing HeLa cells, which is in contrast to the results of study showing that Tax increased the phosphorylation of $\mathrm{Rb}$ family members [19]. Therefore, there is a strong possibility that Tax-activated $\mathrm{p} 21^{\mathrm{CIP} 1 / \mathrm{WAF} 1}$ may function to inhibit the cyclin D2/cdk4 complex, thereby inducing cell cycle arrest.

Our microarray result also shows that Tax upregulated the expression of BCL6 gene encodes a sequencesspecific transcriptional repressor by 2.7 fold. This supported by the findings in previous study [52], which described that an interaction of Tax with the POZ domain of BCL6 enhances the repressive activity of BCL6 and increased the levels of apoptosis induced by BCL6 in osteosarcoma cells. The BCL6 POZ domain mediates transcriptional repression by interacting with several corepressors including silencing mediator for retinoid and thyroid receptor and nuclear hormone receptor corepressor, BCL6 corepressor together with many histone deacetylases. BCL6 colocalizes with these corepressors in punctate nuclear structures that have been identified as sites of ongoing DNA replication. Interestingly, BCL6 appeared to recruite Tax into punctate nuclear structures and significantly downregulate both basal and Taxinduced NF-kB and long terminal repeat activation [52]. 
Thus, the high expression of BCL6 in HTLV infected cells may contribute to the silencing of viral gene expression and to the long clinical latency associated with HTLV infection.

This study allows greater understanding of the biological events affected by HTLV-1 Tax, particularly the regulation of cellular proliferation and apoptosis. Since we found evidence of several similarities, as well as differences, between Tax-expressing HeLa cells and HTLV infection in $\mathrm{T}$ cell lines, we believe that the overexpression of Tax will be useful for preliminary studies on the effects of HTLV infection in T cell lines. However, since Zane et al. recently demonstrated that infected $\mathrm{CD} 4^{+} \mathrm{T}$ cells in vivo are positively selected for cell cycling but not cell death [53], our experimental approaches in HeLa cells may not be reflective of normal physiology of Tax or HTLV-1 in vivo infected cells. Therefore, further detailed studies are required to define the direct and indirect effects of Tax-mediated cellular processes to gain a better understanding of the contribution of Tax to HTLV-1 pathogenesis in vivo.

\section{Conclusion}

The present study showed that Tax arrested cells at the $\mathrm{G}_{1}$ phase of the cell cycle, thereby inducing apoptosis. Taken together, the results demonstrate that Tax exerts a significant impact on cellular factors that regulate the cell cycle and the induction of apoptosis. Importantly, to the best of our knowledge, this is the first study to highlight the morphological dynamics of Tax-induced cell death after cell cycle arrest at the $G_{1}$ phase.

This overview can be extended to Tax-mediated signaling, and further study of the interactions between Tax and cellular factors will provide insights into the mechanisms by which Tax regulates host cell behavior, as well as the mechanisms underlying lymphoma induction and progression induced by HTLV-1.

\section{Methods}

\section{Cell lines and transfections}

Human cervical HeLa cells and Fucci2-expressing HeLa cells (HeLa/Fucci2) [33] were maintained in Dulbecco's modified Eagle's medium (DMEM) (Invitrogen) supplemented with $10 \%$ heat-inactivated fetal bovine serum (FBS) and 100 units/ml penicillin/streptomycin (Sigma). Cells were transiently transfected with a Tax expression vector, or a control vector, using Fugene HD (Roche) according to the manufacturer's instructions.

\section{Plasmid construction}

The HTLV-1 tax gene was amplified from the HTLV-1 infectious molecular clone, K30 [54], using the primers HTax-F (5'-3', AACTCGAGGCCACCATGGCCCATTTC CCAGGGTTTGGAC) and HTax-R (5'-3', AAGCGGCCG
CTCACTTGTCGTCATCGTCTTTGTAGTCGACTTCT GTTTCTCGGAAATGTTTTTCACTGG). The underlined sequences correspond to restriction enzyme sites specific for XhoI and NotI, respectively. A Flag sequence was included at the 3' end of the tax gene. Full-length tax was then cloned into the XhoI and NotI restriction sites in the pCAGGS mammalian expression vector [55]. To generate the pCAGGS-Tax-IRES-CFP vector and the pCAGGSIRES-CFP control vector, the IRES was amplified from the pRetroX-IRES-ZsGreen1 vector (Clontech) and CFP was amplified from the pCS2+ vector (Clontech). The IRES and CFP sequences were then inserted into the pCAGGS control vector or a pCAGGS vector containing Flag-tagged Tax. The vector pEGFP-N1 encodes a red-shifted variant of wild-type GFP that was modified for brighter fluorescence [56] and which was used as a reporter to identify transfected cells by flow cytometry. The pSV- $\beta$-galactosidase vector (Promega) encoding a bacterial $\beta$-galactosidase and pRL-SV40 (Promega) encoding Renilla luciferase were used to normalize the transfection efficiency. pGV-HL21 encodes five tandemly repeated 21 bp enhancers of HTLV1 , each of which contain a CRE motif and pGV(-) and have been previously decribed [57].

\section{RNA extraction}

HeLa cells were transiently transfected with Tax or the control vector and incubated for $30 \mathrm{~h}$. RNA from total cell extracts was isolated using the RNeasy Mini Kit (Qiagen) according to the manufacturer's instructions. RNA was quantified using a spectrophotometer and stored at $-80^{\circ} \mathrm{C}$. For gene chip analysis, the quality of RNA was determined using the Agilent Bioanalyzer (Agilent Technologies).

\section{Microarray analysis}

RNA samples were analyzed by microarray using the GeneChip Human Genome U133A 2.0 Array (Affymetrix). Microarray hybridization and fluorescence detection were performed as described in the Affymetrix Gene-Chip Expression Analysis Technical Manual. Microarray data were deposited in NCBI's Gene Expression Omnibus and assigned GEO Series accession number GSE34750. GeneSpring GX 11.0 software (Agilent Technologies) was used to identify statistically significant differences in gene expression between samples. For multiple measurements to detect significantly upregulated and downregulated genes, the Bonferroni correction was performed by adjusting the significance level $(\mathrm{p}<0.05)$. Fold changes in gene expression, hierarchical clustering, and gene ontology annotations were determined.

\section{qRT-PCR}

Total RNA was prepared using the RNeasy Mini Kit (Qiagen) at 12, 24, 36 and $48 \mathrm{~h}$ after transfection with 
Tax or the control vector. RT-PCR was performed using specific primers and OneStep SYBR Green PCR mix (Takara) following the manufacturer's instructions. The qRT-PCR was performed using a 7500 Fast Real-time PCR System (Applied Biosystems). All data were normalized to GAPDH mRNA.

\section{Immunoblot analysis}

Transfected cells were lysed and proteins were separated on $6 \%, 10 \%$, or $17 \%$ SDS-polyacrylamide gels and then transferred to a PVDF membrane (Immobilon-P, Millipore Corp.) using a Trans-blot SD semi-dry transfer cell (Bio-Rad). Following the transfer, the membranes were blocked in $5 \%$ non-fat dry milk in PBS containing 0.1\% Tween-20 for $1 \mathrm{~h}$ and then incubated with a 1:1000 dilution of primary antibody against Flag (M2, Sigma), $\mathrm{Rb}$ (c-15, Santa Cruz Biotechnology), or actin (c-11, Santa Cruz Biotechnology) for $1 \mathrm{~h}$. The membranes were then washed and incubated with anti-mouse, anti-rabbit, or anti-goat horseradish peroxidase-conjugated secondary antibodies (Jackson, ImmunoResearch) and developed using the SuperSignal West Pico Chemiluminescent substrate Kit (Pierce).

\section{Immunofluorescence}

Cells $\left(1 \times 10^{5}\right)$ were seeded onto $22 \mathrm{~mm}$ diameter coverslips in 24 -well plates and incubated at $37^{\circ} \mathrm{C}$ for $24 \mathrm{~h}$ before transfection. Cells were transiently transfected with either a Tax expression vector or a control vector using the Fugene HD reagent (Roche). Twenty-four hours later, the cells were washed twice with PBS, fixed in $3.7 \%$ formaldehyde, permeabilized using $0.2 \%$ Triton X-100, and stained with an anti-Flag MAb (M2, Sigma) followed by an anti-mouse IgG1 antibody conjugated to Alexa Fluor 488 or 494 (Molecular Probes). Subcellular localization was analyzed by confocal laser scanning microscopy (FV1000, Olympus).

\section{Luciferase assay}

HeLa cells $\left(1 \times 10^{5}\right)$ were transfected with $1 \mu \mathrm{g}$ of the reporter plasmid, pGV-HL21 (HTLV-1 enhancer) or pGV $(-), 0.3 \mu \mathrm{g}$ of the reference plasmid, pRL-SV40, and $0.5 \mu \mathrm{g}$ of the Tax expression vector. At $48 \mathrm{~h}$ after transfection, cells were recovered and the activity of firefly and Renilla luciferase was measured in the lysates as previously described [58]. For each sample, firefly luciferase activity (pGV-HL21) was normalized by reference to Renilla luciferase activity (pRL-SV40).

\section{Cell cycle analysis}

HeLa cells $\left(4 \times 10^{5}\right)$ were incubated in a 6-well plate at $37^{\circ} \mathrm{C}$ for $24 \mathrm{~h}$ followed by co-transfection for $48 \mathrm{~h}$ with $2 \mu \mathrm{g}$ of the Tax expression vector or the control vector and $0.2 \mu \mathrm{g}$ of the pEGFP-N1 vector. Cells were collected and washed with PBS without $\mathrm{Ca}^{2+}$ and $\mathrm{Mg}^{2+}$ and then fixed with $1 \%$ paraformaldehyde followed by $70 \%$ ethanol. After fixation, cells were washed twice with PBS, treated with $200 \mu \mathrm{g} / \mathrm{ml}$ of RNase for $1 \mathrm{~h}$ at $37^{\circ} \mathrm{C}$, and stained with $50 \mu \mathrm{g} / \mathrm{ml}$ of PI. Fluorescence was analyzed using a FACSCalibur (Becton-Dickinson) flow cytometer and Cell Quest software (Becton-Dickinson). Samples were gated to eliminate cells in which GFP emitted strong fluorescence. The acquired FACS data were analyzed using ModFit LT software (Verity Software House).

\section{Analysis of apoptosis}

Flow cytometry was used to detect Annexin V-positive apoptotic cells. Transfected cells were incubated for $48 \mathrm{~h}$ and then the cell monolayers were detached with trypsin and ethylendiaminetetraacetic acid (EDTA), washed twice in PBS, and re-suspended in binding buffer $\left(1 \times 10^{6}\right.$ cells $\left./ \mathrm{ml}\right)$. An aliquot of $1 \times 10^{5}$ cells was stained with 7-AAD and Annexin V-PE (BD Biosciences) for $15 \mathrm{~min}$ at room temperature according to the manufacturer's instructions and then analyzed on a FACSCalibur flow cytometer (BD Biosciences) with Cell Quest software (BD Biosciences). Cells were considered to be in the early stages of apoptosis if they showed staining for Annexin V-PE but not 7-AAD. The double-positive population was considered to be in the late stages of apoptosis, or already dead.

Caspase-3 activity was measured using a caspase3/CPP32 fluorometric assay kit, according to the manufacturer's instructions. Briefly, transfected HeLa cells were harvested, washed twice with PBS, and treated with lysis buffer. Cell lysates were centrifuged at $15000 \times \mathrm{g}$ for $10 \mathrm{~min}$ at $4^{\circ} \mathrm{C}$, supernatants were collected, and protein concentrations were determined with the Pierce BCA protein assay kit (Thermo Scientific). For each experimental point, $50 \mu \mathrm{g}$ of total protein extract was incubated with the substrate for $2 \mathrm{~h}$ at $37^{\circ} \mathrm{C}$. Caspase activity was quantified spectrophotometrically at a wavelength of $405 \mathrm{~nm}$ using a multi-label counter (Model 1420, Wallac Arvo, Perkin Elmer Life Sciences).

\section{Imaging of cultured cells}

HeLa/Fucci2 cells were transiently transfected with Tax-IRES-CFP or the control vector and were subjected to long-term, time-lapse imaging using a computerassisted fluorescence microscope (Olympus, LCV110) equipped with an objective lens (Olympus, UAPO $40 \times / 340$ N.A. $=0.90)$, a halogen lamp, a red LED (620 nm), a CCD camera (Olympus, DP30), differential interference contrast (DIC) optical components, and interference filters. For fluorescence imaging, the halogen lamp was used with three filter cubes for observing mCherry (orange), Venus (green), and CFP (blue) fluorescence. For DIC imaging, the red LED was used with a 
filter cube containing an analyzer. Image acquisition and analysis were performed using MetaMorph 7.7.4 software (Universal Imaging).

\section{Competing interests}

The authors declare that they have no competing interests.

\section{Authors' contributions}

MA performed the experiments, analyzed the data, and wrote the manuscript. HM performed the GRT-PCR and analyzed the data. YA conceived the study, participated in the experimental design, analyzed and interpreted the results, coordinated experiments, and wrote the manuscript. All authors have read and approved the final manuscript.

\section{Acknowledgments}

The authors thank Dr. Eri Takeda for kind help and suggestions; Dr. Shinnosuke Takeshima for submission of microarray data in the NCBI's Gene Expression Omnibus and kind help of preparation of manuscript; Mr. Tomoyuki Murakami for help with drawing the figures of the manuscript; Drs. Guangai Xue and Muhammad Atif Zahoor for help with the microarray analysis; and other members of the Viral Infectious Diseases Unit, RIKEN, for their help with the experiments. The authors thank Dr. Atsushi Miyawaki for kindly providing the plasmids (pRSETB-CFP and pCS2+) and HeLa/Fucci2 cells, and Drs. Asako Sakaue-Sawano and Dr. Roger Y. Tsien for kindly providing the HeLa/Fucci2 cells. We would like to thank Mr. Keisuke Fukumoto for help with the microarray analysis; Mr. Tetsuya Tajima for excellent technical assistance with the Imaging; We are grateful to the Support Unit for Bio-material Analysis, RIKEN BSI Research Resources Center for help with sequence and microarray analyses; the RIKEN BSI-Olympus Collaboration Center for help with imaging; and the RIKEN BioResource Center Cell Bank for help with the distribution of HeLa/Fucci2. We thank the $\mathrm{NIH}$ AIDS Research and Reference Reagent Program for providing the HTLV-1 infectious molecular clone K-30. This work was supported by a Grant-in-Aid for Scientific Research (A and B) and by a grant from the Program for the Promotion of Basic and Applied Research for Innovations in Bio-oriented Industry.

\section{Author details}

'Viral Infectious Diseases Unit, RIKEN, 2-1 Hirosawa, Wako, Saitama 351-0198, Japan. ${ }^{2}$ Department of Medical Genome Sciences, Graduate School of Frontier Science, Laboratory of Viral Infectious Diseases, The University of Tokyo, 2-1 Hirosawa, Wako, Saitama 351-0198, Japan. ${ }^{3} J a p a n$ Foundation for AIDS Prevention, Chiyoda-ku, Tokyo, Japan.

Received: 6 March 2012 Accepted: 7 June 2012

Published: 22 June 2012

\section{References}

1. Poiesz BJ, Ruscetti FW, Gazdar AF, Bunn PA, Minna JD, Gallo RC: Detection and isolation of type $C$ retrovirus particles from fresh and cultured lymphocytes of a patient with cutaneous T-cell lymphoma. Proc Natl Acad Sci USA 1980, 77(12):7415-7419.

2. Gessain A, Barin F, Vernant JC, Gout O, Maurs L, Calender A, de The G: Antibodies to human T-lymphotropic virus type-l in patients with tropical spastic paraparesis. Lancet 1985, 2(8452):407-410.

3. Grassmann R, Aboud M, Jeang KT: Molecular mechanisms of cellular transformation by HTLV-1 Tax. Oncogene 2005, 24(39):5976-5985

4. Boxus M, Twizere JC, Legros S, Dewulf JF, Kettmann R, Willems L: The HTLV1 Tax interactome. Retrovirology 2008, 5:76.

5. Yoshida M: Multiple viral strategies of HTLV-1 for dysregulation of cell growth control. Annu Rev Immunol 2001, 19:475-496.

6. Jeang KT, Giam CZ, Majone F, Aboud M: Life, death, and tax: role of HTLV-I oncoprotein in genetic instability and cellular transformation. J Biol Chem 2004, 279(31):31991-31994.

7. Marriott SJ, Semmes OJ: Impact of HTLV-I Tax on cell cycle progression and the cellular DNA damage repair response. Oncogene 2005, 24 (39):5986-5995.

8. Lemoine FJ, Marriott SJ: Accelerated G(1) phase progression induced by the human T cell leukemia virus type I (HTLV-I) Tax oncoprotein. J Biol Chem 2001, 276(34):31851-31857.
9. Liang MH, Geisbert T, Yao Y, Hinrichs SH, Giam CZ: Human T-lymphotropic virus type 1 oncoprotein tax promotes S-phase entry but blocks mitosis. J Virol 2002, 76(8):4022-4033.

10. Neuveut $C$, Jeang KT: Cell cycle dysregulation by HTLV-I: role of the tax oncoprotein. Front Biosci 2002, 7:d157-163.

11. Neuveut C, Low KG, Maldarelli F, Schmitt I, Majone F, Grassmann R, Jeang KT: Human T-cell leukemia virus type 1 Tax and cell cycle progression: role of cyclin D-cdk and p110Rb. Mol Cell Biol 1998, 18(6):3620-3632.

12. Schmitt I, Rosin O, Rohwer P, Gossen M, Grassmann R: Stimulation of cyclin-dependent kinase activity and G1- to S-phase transition in human lymphocytes by the human T-cell leukemia/lymphotropic virus type 1 Tax protein. J Virol 1998, 72(1):633-640.

13. Iwanaga R, Ohtani K, Hayashi T, Nakamura M: Molecular mechanism of cell cycle progression induced by the oncogene product Tax of human T-cell leukemia virus type I. Oncogene 2001, 20(17):2055-2067.

14. Haller K, Wu Y, Derow E, Schmitt I, Jeang KT, Grassmann R: Physical interaction of human T-cell leukemia virus type 1 Tax with cyclindependent kinase 4 stimulates the phosphorylation of retinoblastoma protein. Mol Cell Biol 2002, 22(10):3327-3338.

15. Haller K, Ruckes T, Schmitt I, Saul D, Derow E, Grassmann R: Tax-dependent stimulation of G1 phase-specific cyclin-dependent kinases and increased expression of signal transduction genes characterize HTLV type 1transformed T cells. AIDS Res Hum Retroviruses 2000, 16(16):1683-1688.

16. Fraedrich K, Muller B, Grassmann R: The HTLV-1 Tax protein binding domain of cyclin-dependent kinase 4 (CDK4) includes the regulatory PSTAIRE helix. Retrovirology 2005, 2:54.

17. Huang $Y$, Ohtani K, Iwanaga R, Matsumura Y, Nakamura M: Direct transactivation of the human cyclin D2 gene by the oncogene product Tax of human T-cell leukemia virus type I. Oncogene 2001, 20(9):1094-1102.

18. Mori N, Fujii M, Hinz M, Nakayama K, Yamada Y, Ikeda S, Yamasaki Y, Kashanchi F, Tanaka Y, Tomonaga M, et al: Activation of cyclin D1 and D2 promoters by human T-cell leukemia virus type I tax protein is associated with IL-2-independent growth of T cells. Int J Cancer 2002, 99 (3):378-385.

19. Iwanaga R, Ozono E, Fujisawa J, Ikeda MA, Okamura N, Huang Y, Ohtani K: Activation of the cyclin D2 and cdk6 genes through NF-kappaB is critical for cell-cycle progression induced by HTLV-I Tax. Oncogene 2008, 27 (42):5635-5642.

20. Liu M, Yang L, Zhang L, Liu B, Merling R, Xia Z, Giam CZ: Human T-cell leukemia virus type 1 infection leads to arrest in the G1 phase of the cell cycle. J Virol 2008, 82(17):8442-8455.

21. Zhang L, Zhi H, Liu M, Kuo YL, Giam CZ: Induction of p21(CIP1/WAF1) expression by human T-lymphotropic virus type 1 Tax requires transcriptional activation and mRNA stabilization. Retrovirology 2009, 6:35.

22. de La Fuente C, Santiago F, Chong SY, Deng L, Mayhood T, Fu P, Stein D, Denny T, Coffman F, Azimi N, et al: Overexpression of p21 (waf1) in human T-cell lymphotropic virus type 1-infected cells and its association with cyclin A/cdk2. J Virol 2000, 74(16):7270-7283.

23. de La Fuente C, Deng L, Santiago F, Arce L, Wang L, Kashanchi F: Gene expression array of HTLV type 1-infected T cells: Up-regulation of transcription factors and cell cycle genes. AIDS Res Hum Retroviruses 2000, 16(16): 1695-1700

24. Chen X, Zachar V, Zdravkovic M, Guo M, Ebbesen P, Liu X: Role of the Fas/Fas ligand pathway in apoptotic cell death induced by the human T cell lymphotropic virus type I Tax transactivator. J Gen Virol 1997, 78(Pt 12):3277-3285.

25. Chlichlia K, Busslinger M, Peter ME, Walczak H, Krammer PH, Schirrmacher V, Khazaie K: ICE-proteases mediate HTLV-I Tax-induced apoptotic T-cell death. Oncogene 1997, 14(19):2265-2272.

26. Kao SY, Lemoine FJ, Mariott SJ: HTLV-1 Tax protein sensitizes cells to apoptotic cell death induced by DNA damaging agents. Oncogene 2000, 19(18):2240-2248.

27. Nicot C, Harrod R: Distinct p300-responsive mechanisms promote caspase-dependent apoptosis by human T-cell lymphotropic virus type 1 Tax protein. Mol Cell Biol 2000, 20(22):8580-8589.

28. Hall AP, Irvine J, Blyth K, Cameron ER, Onions DE, Campbell ME: Tumours derived from HTLV-I tax transgenic mice are characterized by enhanced levels of apoptosis and oncogene expression. J Pathol 1998, 186(2):209-214.

29. Brauweiler A, Garrus JE, Reed JC, Nyborg JK: Repression of bax gene expression by the HTLV-1 Tax protein: implications for suppression of apoptosis in virally infected cells. Virology 1997, 231(1):135-140. 
30. Tsukahara T, Kannagi M, Ohashi T, Kato H, Arai M, Nunez G, Iwanaga Y, Yamamoto N, Ohtani K, Nakamura $\mathrm{M}$, et al: Induction of $\mathrm{Bcl}-\mathrm{x}(\mathrm{L})$ expression by human T-cell leukemia virus type 1 Tax through NF-kappaB in apoptosis-resistant T-cell transfectants with Tax. J Virol 1999, 73(10): 7981-7987.

31. Kasai T, Jeang KT: Two discrete events, human T-cell leukemia virus type I Tax oncoprotein expression and a separate stress stimulus, are required for induction of apoptosis in T-cells. Retrovirology 2004, 1:7.

32. Sakaue-Sawano A, Kurokawa H, Morimura T, Hanyu A, Hama H, Osawa H, Kashiwagi S, Fukami K, Miyata T, Miyoshi H, et al: Visualizing spatiotemporal dynamics of multicellular cell-cycle progression. Cell 2008 132(3):487-498.

33. Sakaue-Sawano A, Kobayashi T, Ohtawa K, Miyawaki A: Drug-induced cell cycle modulation leading to cell-cycle arrest, nuclear mis-segregation, or endoreplication. BMC Cell Biol 2011, 12:2.

34. Burton M, Upadhyaya CD, Maier B, Hope TJ, Semmes OJ: Human T-cell leukemia virus type 1 Tax shuttles between functionally discrete subcellular targets. J Virol 2000, 74(5):2351-2364.

35. Harbour JW, Luo RX, Dei Santi A, Postigo AA, Dean DC: Cdk phosphorylation triggers sequential intramolecular interactions that progressively block $\mathrm{Rb}$ functions as cells move through $\mathrm{G1}$. Cell 1999, 98 (6):859-869

36. de la Fuente C, Wang L, Wang D, Deng L, Wu K, Li H, Stein LD, Denny T, Coffman F, Kehn K, et al: Paradoxical effects of a stress signal on pro- and anti-apoptotic machinery in HTLV-1 Tax expressing cells. Mol Cell Biochem 2003, 245(1-2):99-113.

37. Kawakami A, Nakashima T, Sakai H, Urayama S, Yamasaki S, Hida A, Tsuboi M, Nakamura $H$, Ida H, Migita $K$, et al: Inhibition of caspase cascade by HTLV-I tax through induction of NF-kappaB nuclear translocation. Blood 1999, 94(11):3847-3854.

38. Kuo YL, Giam CZ: Activation of the anaphase promoting complex by HTLV-1 tax leads to senescence. EMBO J 2006, 25(8):1741-1752.

39. Chang HY, Nishitoh $H$, Yang $X$, Ichijo $H$, Baltimore D: Activation of apoptosis signal-regulating kinase 1 (ASK1) by the adapter protein Daxx. Science 1998, 281(5384):1860-1863.

40. Chang L, Karin M: Mammalian MAP kinase signalling cascades. Nature 2001, 410(6824):37-40

41. Seoane J, Le HV, Shen L, Anderson SA, Massague J: Integration of Smad and forkhead pathways in the control of neuroepithelial and glioblastoma cell proliferation. Cell 2004, 117(2):211-223.

42. Pardali K, Kowanetz M, Heldin CH, Moustakas A: Smad pathway-specific transcriptional regulation of the cell cycle inhibitor p21(WAF1/Cip1). Cell Physiol 2005, 204(1):260-272.

43. Yang Q, Manicone A, Coursen JD, Linke SP, Nagashima M, Forgues M, Wang $X W$ : Identification of a functional domain in a GADD45-mediated G2/M checkpoint. J Biol Chem 2000, 275(47):36892-36898.

44. Jin S, Antinore MJ, Lung FD, Dong $X$, Zhao H, Fan F, Colchagie AB, Blanck $P$, Roller PP, Fornace AJ Jr, et al: The GADD45 inhibition of Cdc2 kinase correlates with GADD45-mediated growth suppression. J Biol Chem 2000, 275(22):16602-16608.

45. Smith ML, Chen IT, Zhan Q, Bae I, Chen CY, Gilmer TM, Kastan MB, O'Connor PM, Fornace AJ Jr: Interaction of the p53-regulated protein Gadd45 with proliferating cell nuclear antigen. Science 1994, 266(5189):1376-1380.

46. Glossop JR, Cartmell SH: Effect of fluid flow-induced shear stress on human mesenchymal stem cells: differential gene expression of IL1B and MAP3K8 in MAPK signaling. Gene Expr Patterns 2009, 9(5):381-388.

47. Simonis N, Rual JF, Lemmens I, Boxus M, Hirozane-Kishikawa T, Gatot JS, Dricot A, Hao T, Vertommen D, Legros S, et al: Host-pathogen interactome mapping for HTLV-1 and 2 retroviruses. Retrovirology 2012, 9(1):26.

48. Ng PW, Iha H, Iwanaga $Y$, Bittner M, Chen $Y$, Jiang $Y$, Gooden $G$, Trent JM, Meltzer $P$, Jeang $K T$, et al: Genome-wide expression changes induced by HTLV-1 Tax: evidence for MLK-3 mixed lineage kinase involvement in Tax-mediated NF-kappaB activation. Oncogene 2001, 20(33):4484-4496.

49. Seoane J: $\mathrm{p} 21(\mathrm{WAF} 1 / \mathrm{CIP} 1)$ at the switch between the anti-oncogenic and oncogenic faces of TGFbeta. Cancer Biol Ther 2004, 3(2):226-227.

50. Kehn K, Deng L, de la Fuente C, Strouss K, Wu K, Maddukuri A, Baylor S, Rufner R, Pumfery A, Bottazzi ME, et al: The role of cyclin D2 and p21/waf1 in human T-cell leukemia virus type 1 infected cells. Retrovirology 2004, 1:6.

51. Helt AM, Galloway DA: Mechanisms by which DNA tumor virus oncoproteins target the $\mathrm{Rb}$ family of pocket proteins. Carcinogenesis 2003, 24(2):159-169.
52. Dean J, Hashimoto K, Tsuji T, Gautier V, Hall WW, Sheehy N: Functional interaction of HTLV-1 tax protein with the POZ domain of the transcriptional repressor BCL6. Oncogene 2009, 28(42):3723-3734

53. Zane L, Sibon D, Jeannin L, Zandecki M, Delfau-Larue MH, Gessain A, Gout $O$, Pinatel C, Lancon A, Mortreux F, et al: Tax gene expression and cell cycling but not cell death are selected during HTLV-1 infection in vivo. Retrovirology 2010, 7:17

54. Zhao TM, Robinson MA, Bowers FS, Kindt TJ: Characterization of an infectious molecular clone of human T-cell leukemia virus type I. J Virol 1995, 69(4):2024-2030

55. Niwa H, Yamamura K, Miyazaki J: Efficient selection for high-expression transfectants with a novel eukaryotic vector. Gene 1991, 108(2):193-199.

56. Cormack BP, Valdivia RH, Falkow S: FACS-optimized mutants of the green fluorescent protein (GFP). Gene 1996, 173(1 Spec No):33-38.

57. Tajima S, Aida Y: The region between amino acids 245 and 265 of the bovine leukemia virus (BLV) tax protein restricts transactivation not only via the BLV enhancer but also via other retrovirus enhancers. J Virol 2000, 74(23):10939-10949.

58. Tajima S, Zhuang WZ, Kato MV, Okada K, Ikawa Y, Aida Y: Function and conformation of wild-type $\mathrm{p} 53$ protein are influenced by mutations in bovine leukemia virus-induced B-cell lymphosarcoma. Virology 1998, 243 (1):735-746.

doi:10.1186/1471-2164-13-275

Cite this article as: Arainga et al:: Visualizing spatiotemporal dynamics of apoptosis after G1 arrest by human T cell leukemia virus type 1 Tax and insights into gene expression changes using microarray-based gene expression analysis. BMC Genomics 2012 13:275

\section{Submit your next manuscript to BioMed Central and take full advantage of:}

- Convenient online submission

- Thorough peer review

- No space constraints or color figure charges

- Immediate publication on acceptance

- Inclusion in PubMed, CAS, Scopus and Google Scholar

- Research which is freely available for redistribution 